\title{
INFLUENCE OF WAVE TRANSFORMATION PROCESSES ON EVOLUTION OF UNDERWATER BEACH PROFILE
}

\author{
Yana Saprykina $^{1}$ and Olga Kuznetsova ${ }^{1,2}$
}

\begin{abstract}
On the base of field experimental data were confirmed that the main wave parameters for cross-shore sediment transport are the significant wave height, spectral peak period and wave steepness. Waves with narrowband spectrum more effect on changes of underwater profile. For a qualitative assessment of erosion/accumulation the Dean parameter, the Ursell and Iribarren numbers can be used. However the physical processes of wave transformation play an important role. The most significant are nonlinear wave transformation and wave breaking, especially the type of wave breaking.
\end{abstract}

Keywords: nonlinear wave transformation; underwater beach profile; cross-shore sediment transport, wave breaking, underwater bar

\section{INTRODUCTION}

Coastal dynamics is important for many coastal engineering problems. According to many empirical relations and semi-empirical models using in engineering practice a sediment transport in coastal zone depends on wave parameters. Sediments transport in coastal zone as well as cross-shore profile shape of sloping sandy beach are determined by wave transformation effects, such as nonlinearity due to wave-wave interactions, shoaling, wave breaking, etc., which also depend on initial wave parameters. There are many empirical formulas that can be used for computation sediment transport processes in coastal zone. These formulas include various wave parameters obtained on different time scales (for example, CEM, 2002). In numerical modelling of sediments transport in coastal zone wave parameters are extremely important for correct initial and boundary conditions definition. Meanwhile today we do not have well-definite single-mining answer on the question which wave parameters are the most important and how they affect sediment transport on the different time scales.

During the evolution in coastal zone waves transform under non-linear dispersive processes, that can lead to variability of individual wave parameters (Saprykina et al., 2009). There is a periodical wave energy exchanges between first and second non-linear harmonics of wave movement appearing during wave propagation shoreward, especially at wave transformation on mild bottom slope. In (Saprykina et. al., 2013) were defined four scenarios of nonlinear wave transformation in coastal zone and maintain that scenario implementation depends on Iribarren number at sea boundary of the coastal zone. But how periodical exchanges of wave energy can influence on sediment transport and underwater profile deformations was not investigated in detail. Only in some papers mentioned that it possibly can lead to formation of underwater bars (Boczar-Karakiewicz, Davidson-Arnott, 1987).

Sediments transport under breaking waves can depends on type of wave breaking, because waves breaking by spilling have symmetry not the same as waves breaking by plunging (Kuznetsov et al., 2015). Due to dependence of sediment transport on wave asymmetry (Bailard, 1981) the difference in shape of breaking waves also can be important.

Lack of physical model describing wave transformation in coastal zone and its influence on the underwater relief is connected, firstly, with small amount of field data, which could make possible a detailed analysis of real processes. The main purpose of this work is to study the influence of process wave transformations and wave parameters on the dynamics of underwater beach profile on time scale of several storms on the base of unique field experiments data.

\section{EXPERIMENTS AND METHODS}

The field experiments for synchronous measurements of waves and changes of cross-shore underwater bottom profile was carried out on special research pier of Institute of Oceanology of Bulgarian Academy of Sciences located in Bulgarian Black Sea coastal zone near settlement Shkorpilovtsy in September-October 2007 and October-November 2016. Pier's length of $230 \mathrm{~m}$ provides measuring distance about $200 \mathrm{~m}$ from the shore up to water depth of $5.5 \mathrm{~m}$. In 2007 for wave

\footnotetext{
${ }^{1}$ Zenkovich Coast and Shelf Laboratory, Shirshov Institute of Oceanology RAS, Nakhimovskii pr., 36, Moscow,

${ }^{2}$ Zubov State Oceanographic Institute, Kropotkinskii per., 6, Moscow, 119034, Russia
} 
measurements 7 capacitance (sampling frequency $200 \mathrm{~Hz}$ ) and 8 resistant type wire gauges (sampling frequency $5 \mathrm{~Hz}$ ) along pier was carried out. The wave measurements were taken synchronously with duration of the records from $20 \mathrm{~min}$ up to one hour. In 2016 year 20 wire capacity type wave gauges with sampling frequency $25 \mathrm{~Hz}$ were used for continuous synchronous wave measurements during all experiment. Wave breaking was fixed by photo and video records.

Morphological changes of bottom profile in both field experiments were measured daily and three time per day during storm conditions by cross-shore profiling along the pier with spatial resolution of 2 $\mathrm{m}$, using special metal pole and rope lot. Underwater slope is covered by anisomerous sands. In the upper part of profile till $2.5 \mathrm{~m}$ depth more than $95 \%$ bottom sediments contain coarse-grained and medium sands, where quartz components predominate.

Field data include several storms events and a few cycles of bottom profile evolution from inclined mild sloping bottom through barred profile to inclined profile again. The changes of shape as well as velocity of bottom profile deformations in dependence on wave parameters and wave transformation processes were accounted.

Shoreline changes were estimated by velocity of shoreline movement:

$$
S h=\left(x 0_{t_{2}}-x 0_{t_{1}}\right) /\left(t_{2}-t_{1}\right)
$$

where $x 0$ - location of $0 \mathrm{~m}$ isobaths, $t_{1}$ and $t_{2}$ - time of surveys.

The velocity of sediments volume change was calculated by:

$$
Q=\left(V_{t_{2}}-V_{t_{1}}\right) /\left(t_{2}-t_{1}\right)
$$

where $V=\int\left(h-h_{\text {mean }}\right) d x$ is specific sediment volume, $h_{\text {mean }}$ - mean profile depth, $x$ - cross-shore coordinate.

Wave parameters that were used for analysis:

a) significant wave height:

$$
\begin{gathered}
H s=4 \sqrt{m_{0}} \\
m_{0}=\int_{0}^{\infty} S(\omega) d \omega
\end{gathered}
$$

where, $S$ - wave spectrum, $\omega$ - angular frequency;

b) period of spectral peak - $T_{p}$;

c) wave steepness

where $L$ - wave length;

$$
\lambda=H_{S} / L
$$

c) Ursell number describing non-linear and dispersive wave properties:

$$
U r=(2 \pi)^{2}\left[\bar{a} k /(k h)^{3}\right]
$$

where $a=H s / 2$ - wave amplitude, $k$ - wave number, $h$ - water depth.

d) Iribarren number - the ratio between average bottom inclination and wave steepness which is included in many empirical relationships related to sediment transport:

$$
I r=\tan \alpha \cdot(H / L)^{-1 / 2}
$$

where $\alpha$ - bottom slope, $H$ - wave height.

Iribarren number was also used to evaluate nonlinear wave transformation scenario: if $\operatorname{Ir}<7 * H / L$ then scenario with periodic energy exchange between nonlinear wave harmonics is possible (Saprykina et al., 2013).

e) Dean parameter for checking relations between wave parameters and processes of erosion/accumulation on underwater profile:

$$
S=H_{\circ d}\left(w_{g} T_{p}\right)
$$


where $H_{\infty}$ - wave height on deep water, $w_{g}$ - sediment fall velocity.

All wave parameters were calculated based on measurements on last wave gauge on distance $200 \mathrm{~m}$ from shore. Wave regimes of swell and winds were considered separately.

\section{DICUSSION OF RESULTS}

\section{Dependence of profile deformations on wave parameters}

The dependences between calculated wave parameters at the entrance of the experimental coastal zone (200 m from shoreline) and velocity of specific sediment volume changes of the underwater profile are presented on Fig. 1. Results show that significant wave height is clearly influences on sediment volume changes (Fig. 1a). For the wave period such dependence is not so obvious (Fig. 1b), but in general increasing of wave period leads to increasing of erosion. That coincides with the existent physical concept of wave action on sandy beaches, although it is more evident for swell rather than for wind waves.

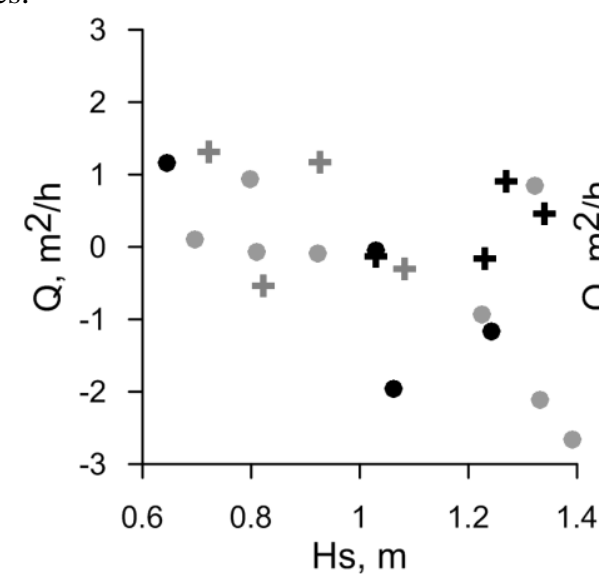

(a)

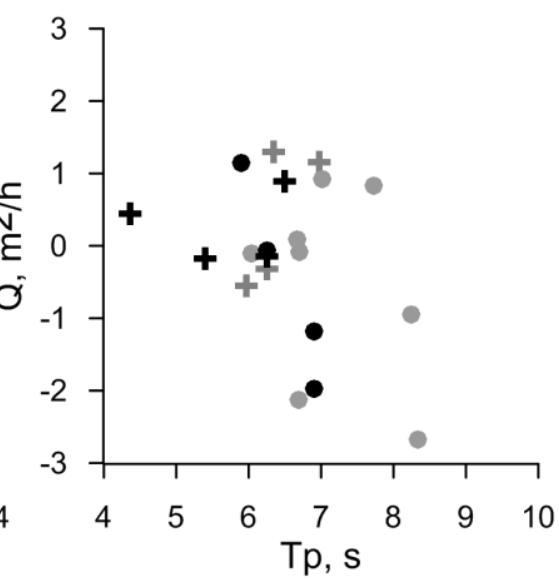

(b)

Figure 1. Dependences of velocity of specific sediments volume change on significant wave height (a) and spectral peak period (b). Crosses - wind waves, dots - swell; black symbols - experiment 2007, grey experiment 2016.

Figure 2 illustrates that the highest and longest of the observed waves does not produce such a large retreat of the shoreline as it might be supposed. Thus, the wave transformation proceeds in a way that it could protect the coast. This point is also confirmed by monitoring of the bottom relief: changes of the slope near the shoreline are produced by waves less than $1.5 \mathrm{~m}$ height on the entrance of study site.

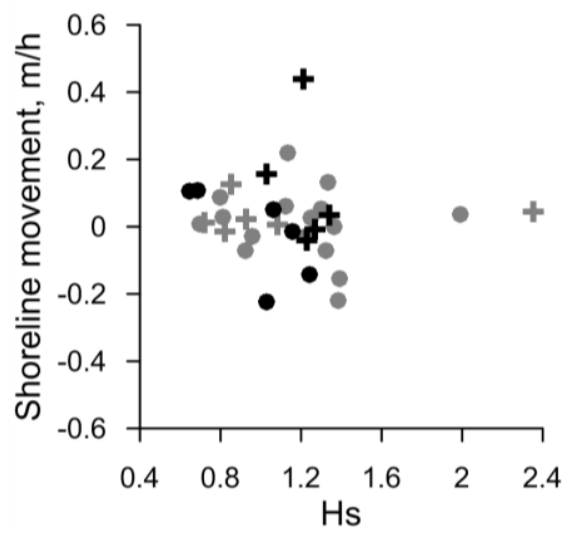

(a)

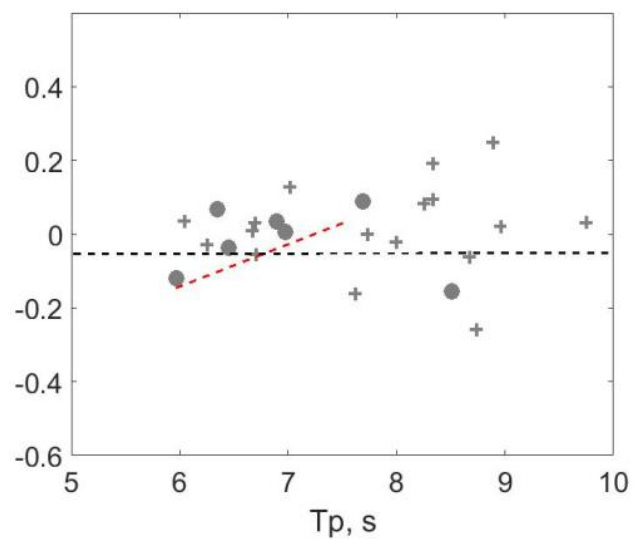

(b)

Figure 2. Dependences of velocity of shoreline movement on significant wave height (a) and spectral peak period (b). Crosses - wind waves, dots - swell; black symbols - experiment 2007, grey - experiment 2016.

A prominent dependence between wave steepness and profile changes cannot be clearly ascertained (Fig. 3a). More clear is dependence on Dean parameter which include wave steepness on deep water. When Dean parameter is less than 2 an accumulation will be, but when Dean parameter is more than $2-$ erosion will occurs. In general Dean parameter can be an indicator of erosion/accumulation processes. 
From available data is visible that significant erosion could be produced by swell and not by wind waves even if it might be twice as steep (0.06).

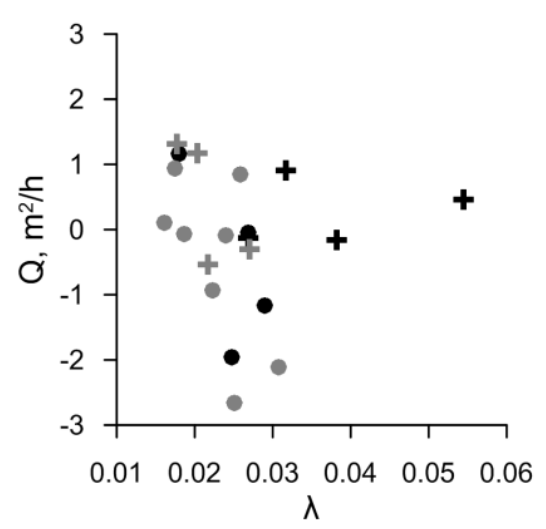

(a)

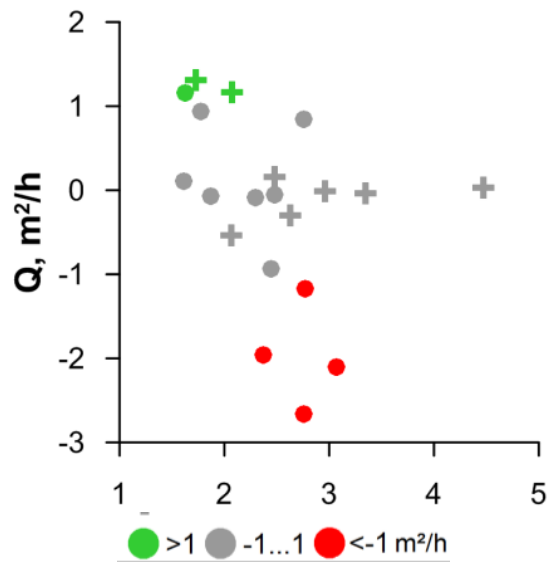

Dean parameter $(S)$

Figure 3. Dependences of velocity of specific sediments volume change on wave steepness (a) and Dean parameter (b). Crosses - wind waves, dots - swell.

Figure 4 shows the relations between Ursell and Irribaren numbers and specific volume of sediments changes. Increase of the Ursell number, which means that wave non-linearity prevails over dispersion, leads to erosion of the profile. The values of Ursell and Irribaren numbers determine the scenario of wave transformation within the coastal zone by development of non-linear wave interactions (Saprykina et al., 2013). From the presented dataset it can be seen, that erosion prevails for $\operatorname{Ir}<0.16$, $\mathrm{Ur}>9$ when at nonlinear wave transformation there is scenario with significant (maximal) amplitudes of second nonlinear harmonics in inner part of coastal zone.

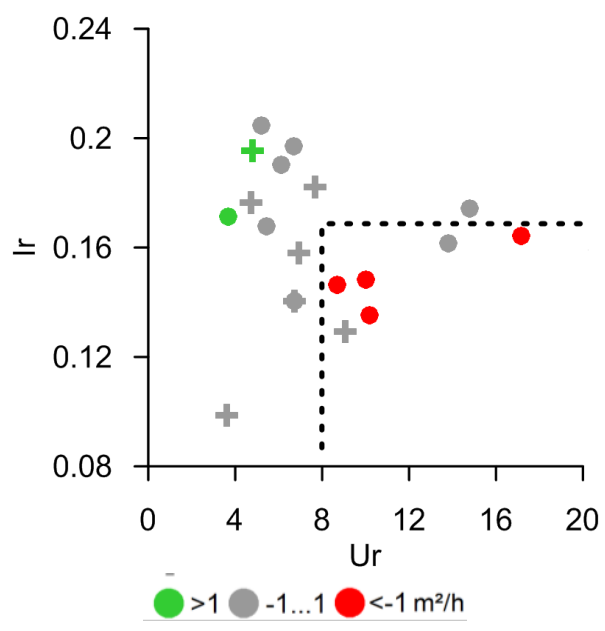

Figure 4.. Dependences of velocity of specific sediments volume change on Iribarren and Ursell numbers. Crosses - wind waves, dots - swell.

According to the presented analysis of field data, it was confirmed that at the main wave parameters, which determine the sediment transport and coastline movements, are the significant wave height, spectral peak period and wave steepness. In general, increase of these parameters is related to an upward trend of the negative wave force on the shore. However, this tendency is not always evident, so it is impossible to unambiguously predict the behavior of the sediment transport only by wave parameters or empirical numbers because the coastal zone dynamics is much more influenced by wave transformation processes, especially nonlinear. 


\section{Dependence of profile deformations on wave non-linearity}

Cross shore sediment transport can be calculated using formula (Bailard, 1981)

$$
q=\frac{1}{2} \cdot f_{w} \rho\left(\frac{\varepsilon_{b}}{\operatorname{tg} \phi} \overline{u|u|^{2}}+\frac{\varepsilon_{s}}{W_{s}} \overline{u|u|^{3}}\right)
$$

Where $u$-orbital near bottom velocity, other coefficients characterized features of sediments.

As was shown in (Stive, 1986)

$$
\begin{aligned}
& \overline{u|u|}^{2} \approx u_{1}^{2} u_{2} \cos \varphi \\
& \overline{u|u|}^{3} \approx u_{1}^{3} u_{2} \cos \varphi \\
& u_{i}=\frac{a_{i} \omega}{\operatorname{sh}(k h)}
\end{aligned}
$$

where $a_{1}$ and $a_{2}$-amplitudes of first and second nonlinear harmonics, $\varphi$ - shift of phases (biphase) between $a_{1}$ and $a_{2}, \omega$ - angular frequency, $k$ - wave number, $h$ - water depth.

As can be seen the sediment discharge $q$ depends on amplitudes of first and second nonlinear wave harmonics and phase shift between them. So, nonlinear transformation of waves strongly influences on it value.

Biphase can be calculated using bispectral analysis as (Kim, Powers, 1976):

$$
\varphi\left(\omega_{1}, \omega_{2}\right)=\arctan \left[\left(\operatorname{Im}\left\{\mathrm{B}\left(\omega_{1}, \omega_{2}\right)\right\}\right) /\left(\operatorname{Re}\left\{\mathrm{B}\left(\omega_{1}, \omega_{2}\right)\right\}\right)\right]
$$

where $B\left(\omega_{1}, \omega_{2}\right)=E\left[A_{\omega_{1}} A_{\omega_{2}} A_{\omega_{1}+\omega_{2}}^{*}\right]$ is the bispectrum, $A$ represents the complex Fourier amplitudes of the free surface elevations, and $E$ is the averaging operator.

For analysis the frequencies of first and second nonlinear wave harmonics were defined from location of spectral maximums in corresponding frequency bands. Values of amplitudes calculated as squared root of integral spectral wave energy corresponding frequency ranges.

Deformations of the bottom relief are connected with the gradient of sediment discharge:

$$
d q / d x \approx d h / d t
$$

where $\mathrm{h}$ is the depth, the positive sign (+) corresponds to the increase in depth, i.e. erosion and removal of sandy material, and the negative sign (-)corresponds to the decrease in depth, i.e. accumulation.

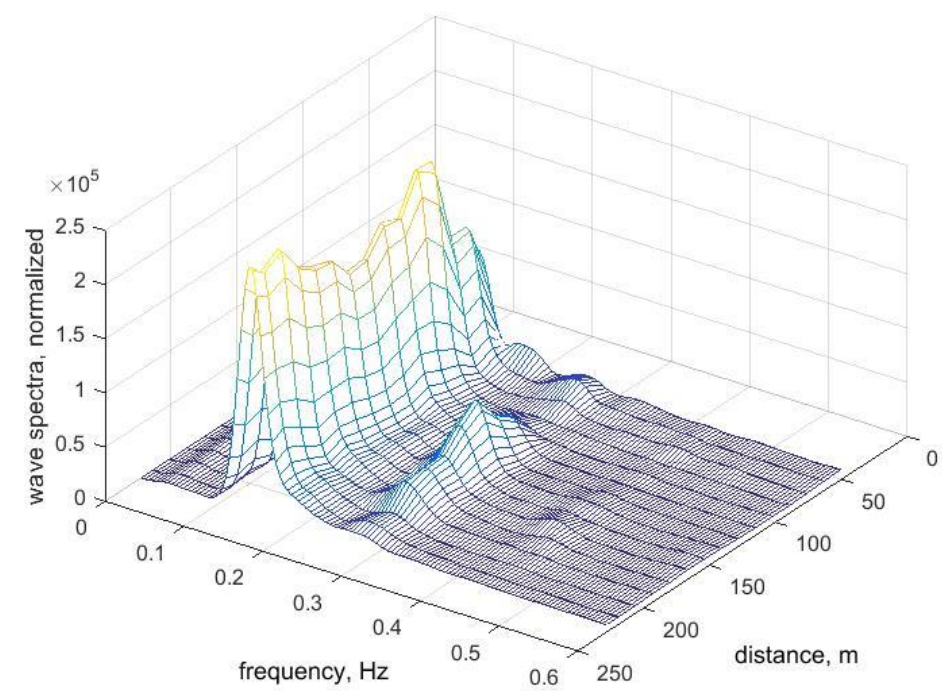

Figure 5. Wave spectra normalized on dispersion, (series 34, registered at 8.00 a.m. 28 September 2007). 
As was shown above, the highest velocity of change of the specific volume of sediments on the underwater profile will be observed when wave transformation scenarios with a maximum of the second nonlinear harmonic inside the coastal zone and a periodic energy exchange between the first and second nonlinear harmonics are observed. During field experiment Shkorpilovtsy 2007 all day on September 28 only this scenario of nonlinear wave transformation was observed. Typical wave spectra are shown on Fig.5. The significant height of the waves at a distance of $200 \mathrm{~m}$ from the coast during the day changed a little from 1 up to $1.2 \mathrm{~m}$. The breaking of all waves occurred on $45 \mathrm{~m}$ (plunging) and largest waves on 140-160 m (plunging or spilling).

From the formula (8) it is clearly seen that the sediment discharge depends on the changes of the second and third moments of the orbital near bottom velocity, which describe the transport of the loaded sediments and suspended sediments, respectively. So, for qualitatively analysis we will describe sediment discharge as a sum of these moments. Typical scenario for the variation of the amplitudes of the first and second nonlinear harmonics with a periodic exchange of energy between them observed on September 28 are shown on Fig. 6c. Corresponding changes of the biphase is shown in Fig. 6d. It is clearly seen that the biphase changes from $-\pi / 2$ to $+\pi / 2$, that according to the formulas (9-10), will always provide a positive sediment discharge i.e. directed to the coast. As shown in (Saprykina et al., 2017) on experimental data, such a change in biphase is characteristic for waves propagating above mild slopping bottom. During a periodic exchange of energy between nonlinear harmonics, when the second harmonic grows, the biphase is negative (distance 150-200 m) and gradually becomes zero when the amplitude of the second harmonic reaches a maximum (distance $140 \mathrm{~m}$ ), and then grows to a value close to $+\pi / 2$. In this time the second harmonic decreases, and the first one grows again (a distance of $110 \mathrm{~m})$.

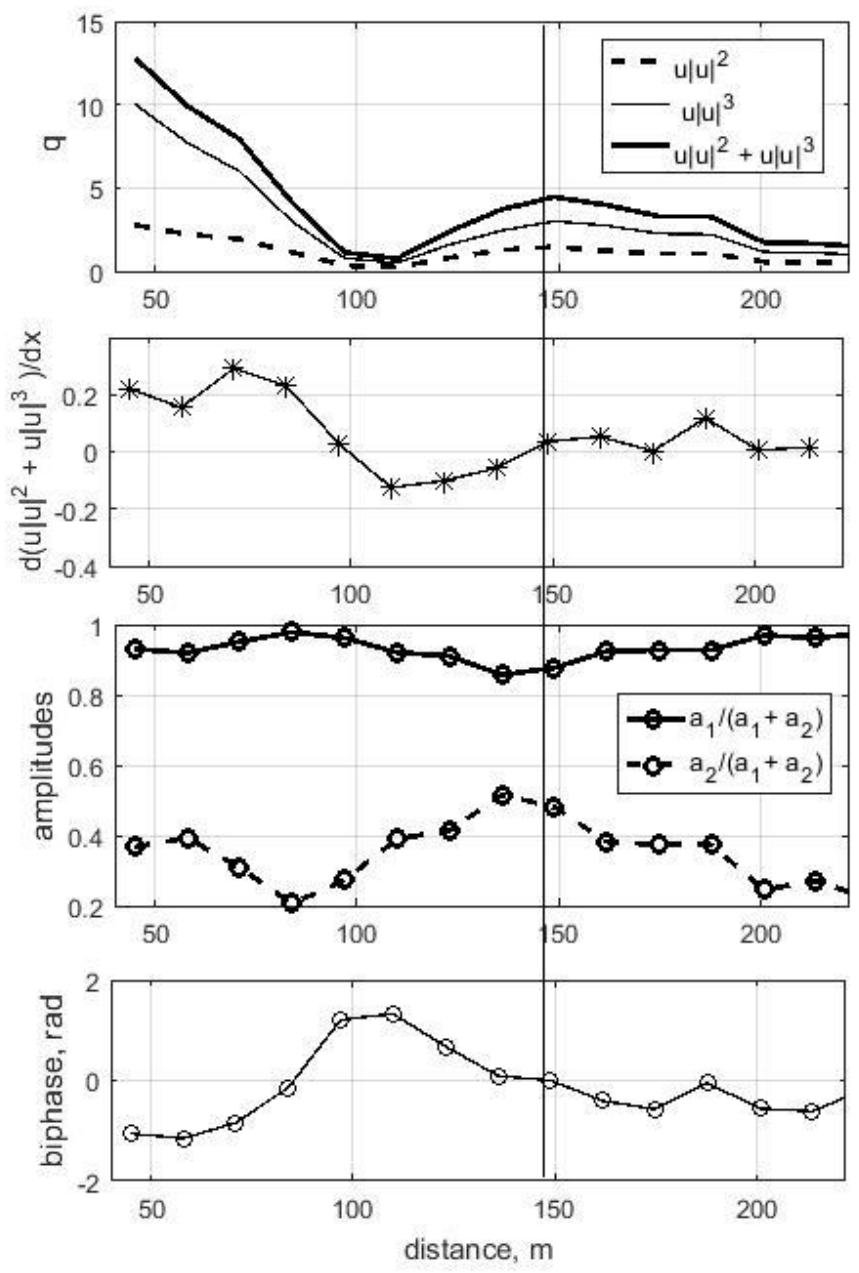

(a)

(b)

(c)

Figure 6. Changes of moments of orbital near bottom velocity (a), bottom deformations (b), amplitudes of first and second wave harmonics (c) and biphase (d), series 34, registered at 8.00 a.m. 28 September 2007. 
With a periodic exchange of energy between nonlinear harmonics, the following scenario of sediment discharge is typical (Fig. 6a): when the second harmonic grows, the discharge also increases, and when the second harmonic decreases, it decreases also. As can be seen on Fig.6a,c,d the maximum values of the main components of sediment discharge coincide with the second harmonic maximum (the cosine of the biphase at this moment is also maximum, equal to one, since the biphase is zero), and the minimum values - corresponds to beginning of its growth and decreasing. According to formula (13) such behavior of sediment discharge leads to the following characteristic bottom deformations: erosion (positive gradient values) occurs when the second nonlinear harmonic grows and sediments are transferred and accumulated in that part of the profile where the second harmonic decreases, which corresponds to negative gradient values (Fig.6b). Further new cycle of growth of the second harmonic also leads to erosion (a distance of 60-90 m).

The conclusions obtained on the basis of the qualitative analysis are fully confirmed by the experimental data (Fig. 7). If we compare the change in the underwater profile during 18 hours from midday of September 27 until the morning of September 28 (Fig7a), then we can see that the resulting depth difference (profile deformation) corresponds to gradient of the sum the bottom velocity moments calculated by the formula (13) (Fig. 6b) taking into account the influence of undertow (Fig.7c). Under the influence of a periodic exchange of energy between the first and second nonlinear harmonics, erosion occurs on the seaward slope of the bar and the material is transferred to its shoreward front.

Undertow, in simple form can be calculated as:

$$
\bar{u}=-\frac{1}{8} \frac{H^{2}}{h^{2}} \sqrt{g h}
$$

where $\mathrm{h}$ - depth, $\mathrm{H}$ - wave height, gives the resulting contribution to the formation of the bottom relief.
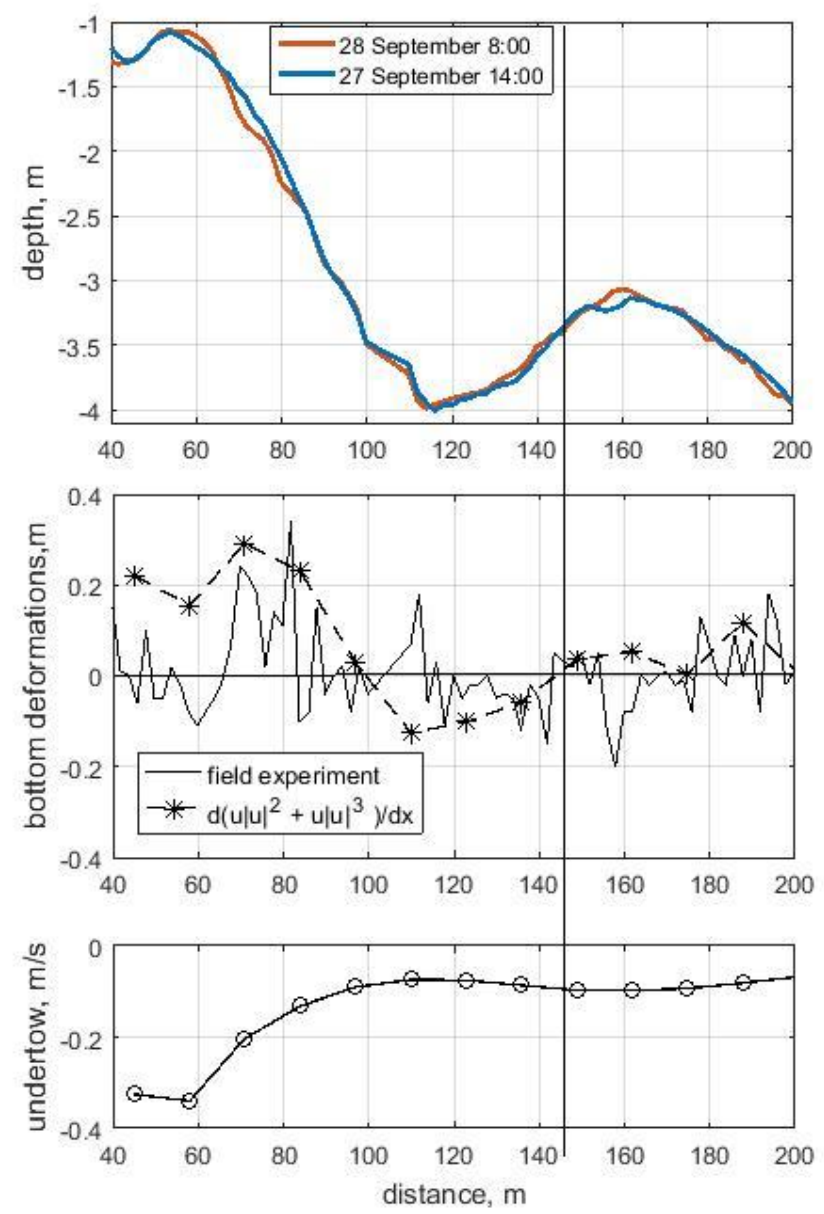

(a)

(b)

(c)

Figure 7. Changes of underwater profile (a), bottom deformations (b) and undertow (c).

Although undertow on 100-200 $\mathrm{m}$ is not very high it may affect the transfer and accumulation of sand on the top of bar. The periodic exchange of wave energy can lead to a change in the symmetry of the bar. Also, the influence of the undertow or avalanching of sand can affect erosion, observed at a 
distance of $110 \mathrm{~m}$. The growth of the second harmonic with the propagation of waves closer to the shore leads to erosion of the underwater slope and transfer of sand closer to the shore. At the interaction of wave induced sediment transport with the undertow directed towards the sea, which has already high values and transfers the sand to seaward, a well-defined underwater bar is formed (accumulation at 60 $\mathrm{m})$. That quite corresponds to the ideas stated in many scientific works about the influence of waves and undertow interactions on the formation of underwater bars.

The wave transport of sediments under nonlinear wave transformation and energy exchange between harmonics has the following characteristic scenario, leading to an increase in value of change in the specific volume of sediment: the growth of the second nonlinear harmonic leads to erosion of the submerged slope at distances increasing its amplitude and subsequent accumulation of material closer to the shore at distances where its amplitude reducing due to the backward energy transfer to first harmonic during the periodic exchange of energy between them. So, in the case of second harmonics growth, the sediments are removed and transferred with subsequent accumulation at the stage of its backward reduction. The undertow contributes to the resulting deformations of the bottom topography, in particular, to formation of underwater bars when it interacts with wave induced cross-shore sediment transport.

\section{Dependence of profile deformations on wave breaking \\ Breaking type and breaking zone location also play a crucial role in coastal morphodynamics.}

Visual observations during both experiments showed that the underwater bars appear when waves break by plunging. Plunging breaking waves form underwater bars, move sediments seaward and "support" existence of bars. Spilling breaking waves move sediments to the shore and smooth out underwater bars. It occurs because waves breaking by different type have different asymmetry against vertical axis, which depends on biphase (Saprykina et al., 2017a, b).
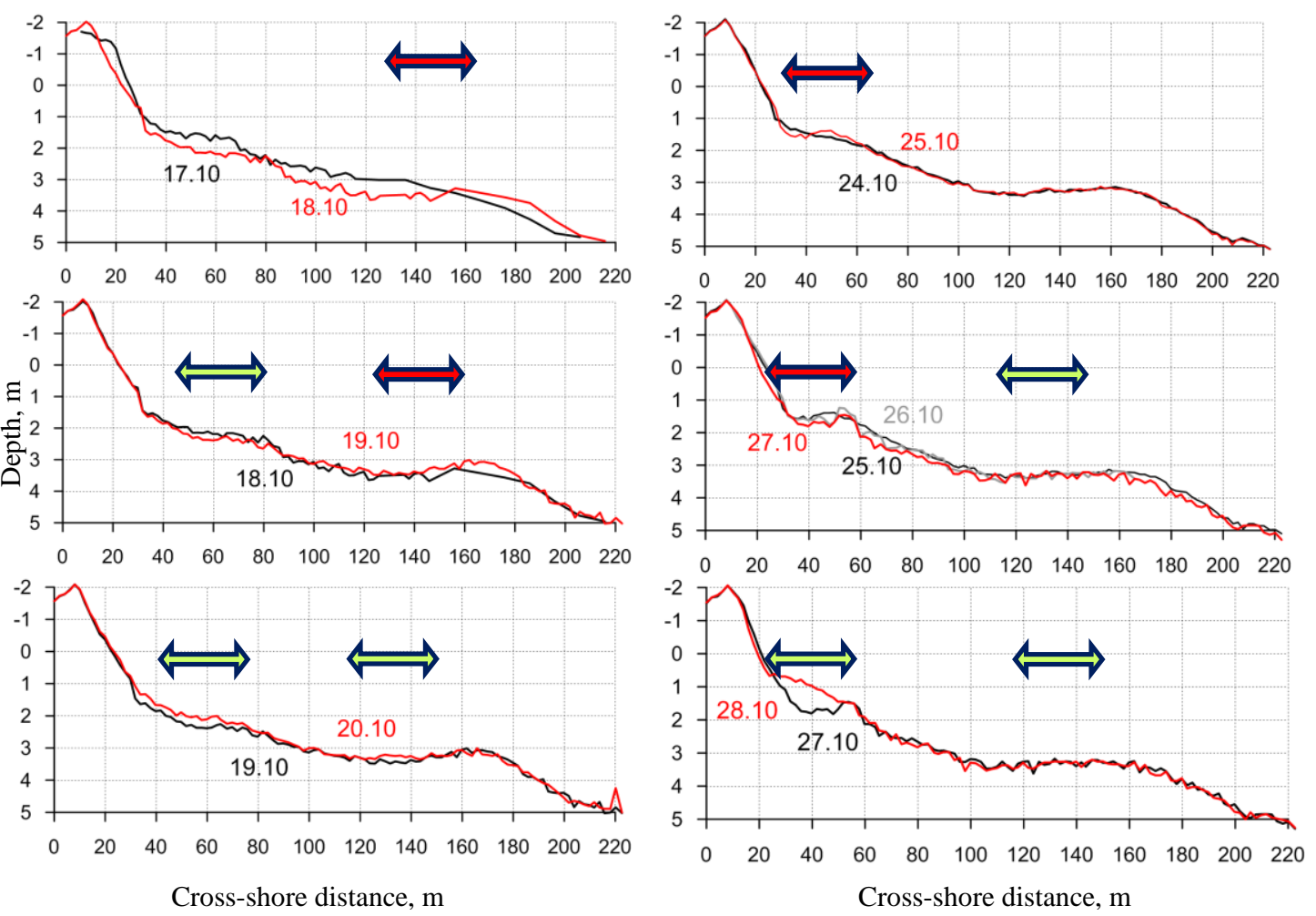

Figure.8. Evolution of underwater bottom profile under plunging (red arrows) and spilling (green arrows) breaking waves.

Plunging breaking waves are asymmetrical on vertical axis and biphase is near $-\pi / 2$. According to formulas (9-10) in this case $q \rightarrow 0$, and undertow will prevail. Spilling breaking waves are near symmetrical on vertical axis and biphase is near zero. In this case there is significant wave induced sediment transport which can prevail and move sediments to the shore. Typical experimental evidences 
of this are shown on Fig. 8 on example of evolution of underwater bottom profile during change of wave breaking type in field experiment Shkorpilovtsy 2016.

\section{CONCLUSIONS}

It was confirmed that the main wave parameters for cross-shore sediment transport are the significant wave height, spectral peak period and wave steepness. The most importanat is the wave height. In general, an increase of these parameters leads to erosion. Waves with narrowband spectrum (swell waves) influence on changes of underwater bottom profile more.

For a qualitative assessment of the processes of erosion/accumulation, the Dean parameter, the Ursell and Iribarren numbers can be used.

However, it is impossible to predict deformations of the underwater bottom relief on the base only wave parameters and empirical numbers, because the physical processes of wave transformation play an important role. The most significant of these are nonlinear wave transformation and wave breaking (especially the type of wave breaking). This should be taken into account for an adequate estimation of sediment transport in coastal zone.

According to field observations, the concept that the wave breaking is a mechanism for the formation of underwater bars is confirmed, and it is clarified that the type of wave breaking in this case is plunging.

\section{ACKNOWLEDGMENTS}

This work was supported by the Russian Science Foundation (the project 14-50-00095) and partly by the Russian Foundation for Basic Researches (the project 18-55-45026).

\section{REFERENCES}

Bailard, J.A. 1981. An energetic total load sediment transport model for a plane sloping beach. J. of Geoph. Res. 86(C11), 10938-10954.

Boczar-Karakiewicz B., Davidson-Arnott R. 1987. Nearshore bar formation by non-linear process - a comparison of model results and field data. Marine Geol., 77, 287-304.

CEM (Coastal Engineering Manual), 2002. Engineer Manual 1110-2-1100, U.S. Army Corps of Engineers, Washington, D.C. (in 6 volumes).

Kim Y. and E. Powers. 1979. Digital bispectral analysis and its application to non-linear wave interaction, IEEE Trans. Plasma Sci. 1, 120-131.

Kuznetsov, S., Saprykina Y., Shtremel M. \& Kuznetsova O. 2015. Spectral structure of breaking waves and its influence on the transport of sediment in coastal zone. Proc. of Conf. OCEANS'15 MTS/IEEE, Genova, May 18-21, Italy.

Saprykina Y.V., Kuznetsov S.Y., Divinskii B.V. 2017b.Influence of processes of nonlinear transformations of waves in the coastal zone on the height of breaking waves. Oceanology. 2017. 57(3), 383-393.

Saprykina, Y.V., Shtremel, M.N., Kuznetsov, S.Y. 2017a. On the possibility of biphase parametrization for wave transformation in the coastal zone. Oceanology 57 (2), .253-264.

Saprykina, Ya.V., Kuznetsov S.Yu., Cherneva Zh.I. \& Andreeva N.K. 2009. Spatio-temporal variability of the amplitude-phase structure of storm waves in the coastal zone of the sea. Oceanology 49(2), 182-192.

Saprykina, Ya.V., Kuznetsov, S.Yu., Andreeva, N.K. \& Shtremel, M.N. 2013. Scenarios of nonlinear wave transformation in the coastal zone. Oceanology 53(4): 422-431.

Stive M.J.F. 1986. A model for cross-shore sediment transport. Proc.of $20^{\text {th }}$ International Conference on Coastal Engineering, 1550-1564. 